\title{
Sistema Agroalimentar Localizado e Desenvolvimento Territorial Sustentável: um estudo da experiência dos produtores de cachaça do município de Morretes - PR
}

\author{
Elaine Cristina de Oliveira Menezes \\ Universidade Federal do Paraná - Matinhos - Paraná - Brasil \\ ORCID: https://orcid.org/0000-0002-1427-0744 \\ Eder Bruno Couto Curvelo \\ Universidade Federal do Paraná - Paranaguá - Paraná - Brasil \\ ORCID: https://orcid.org/0000-0001-6301-7000. \\ Sandro Deretti \\ Universidade Estadual do Paraná - Paranaguá - Paraná - Brasil \\ ORCID: https://orcid.org/0000-0002-8948-9484
}

\section{Resumo}

O objetivo do estudo é o de analisar a trajetória de evolução da produção de cachaça de Morretes, como se organizam os produtores e quais têm sido os obstáculos à incorporação da dimensão socioambiental em tais práticas produtivas. Este estudo tem como pano de fundo o conceito orientador do Desenvolvimento Territorial Sustentável (DTS), apoiado nas dimensões socioeconômica e sociocultural, mobilizando as abordagens teóricas do Sistema Agroalimentar Localizado (SIAL). Para compreender as atividades dos produtores de cachaça de Morretes, foi necessário incorporar a dimensão da sustentabilidade, baseada no enfoque do ecodesenvolvimento. A pesquisa tem caráter empírico, pautada em uma abordagem predominantemente qualitativa. É um estudo exploratório-descritivo, utilizando-se a pesquisa bibliográfica, documental, e entrevistas semiestruturadas. Os resultados do estudo demonstraram que os elementos que caracterizam o SIAL para a produção de cachaça de Morretes são frágeis, sendo insuficientes para sua consolidação. $O$ segmento estudado é uma aglomeração produtiva em que os recursos específicos foram parcialmente ativados. Para promover o DTS, é preciso que os atores locais fortaleçam seus vínculos e trabalhem em busca de uma estratégia coletiva, que beneficie todos os engenhos de cachaça da região. A participação do poder público e das instituições de fomento é fundamental, principalmente, na formulação de políticas públicas efetivas, que favoreçam essa importante atividade regional.

Palavras-chave: Desenvolvimento Territorial Sustentável. Sistema Agroalimentar Localizado. Cachaça. 
Sistema Agroalimentar Localizado e Desenvolvimento Territorial Sustentável: um estudo da experiência dos produtores de cachaça do município de Morretes - PR

\section{Localized Agrifood System and Sustainable Territorial Development: A Study of the Experience of Cachaça Producers in the Municipality of Morretes - Pr}

\section{Abstract}

The objective of the study is to analyze the evolution path of Morretes cachaça production, how producers are organized and what have been the obstacles to the incorporation of the socio-environmental dimension in such productive practices. This study is based on the guiding concept of Sustainable Territorial Development (DTS), based on the socioeconomic and socio-cultural dimensions, mobilizing the theoretical approaches of the Localized AgriFood System (SIAL). In order to understand the activities of Morretes cachaça producers, it was necessary to incorporate the dimension of sustainability, based on the focus on ecodevelopment. The research has an empirical character, based on a predominantly qualitative approach. It is an exploratory-descriptive study, using bibliographic, documentary research and semi-structured interviews. The results of the study showed that the elements that characterize SIAL for the production of cachaça from Morretes are fragile, being insufficient for its consolidation. The segment studied is a productive agglomeration in which specific resources have been partially activated. To promote DTS, it is necessary for local actors to strengthen their ties and work in search of a collective strategy, which benefits all the cachaça mills in the region. The participation of public authorities and development institutions is fundamental, especially in the formulation of effective public policies, which favor this important regional activity.

Keywords: Sustainable Territorial Development. Located Agrifood System. Sugarcane liquor.

\section{Sistema agroalimentario localizado y desarrollo territorial sostenible: un estudio de la experiencia de los productores de cachaça en el municipio de Morretes - Pr \\ Resumen}

El objetivo del estudio es analizar el camino de evolución de la producción de cachaça de Morretes, cómo se organizan los productores y cuáles han sido los obstáculos para la incorporación de la dimensión socioambiental en tales prácticas productivas. Este estudio se basa en el concepto rector del Desarrollo Territorial Sostenible (DTS), basado en las dimensiones socioeconómicas y socioculturales, movilizando los enfoques teóricos del Sistema Agroalimentario Localizado (SIAL). Para comprender las actividades de los productores de cachaça de Morretes, fue necesario incorporar la dimensión de sostenibilidad, basada en el enfoque en el desarrollo ecológico. La investigación tiene un carácter empírico, basado en un enfoque predominantemente cualitativo. Es un estudio exploratorio descriptivo, que utiliza bibliografía, investigación documental y entrevistas semiestructuradas. Los resultados del estudio mostraron que los elementos que caracterizan a SIAL para la producción de cachaça de Morretes son frágiles, siendo insuficientes para su consolidación. El segmento estudiado es una aglomeración productiva en la que se han activado parcialmente recursos específicos. Para promover el DTS, es necesario que los actores locales fortalezcan sus lazos y trabajen en busca de una estrategia colectiva, que beneficie a todas las fábricas de cachaça en la región. La participación de las autoridades públicas y las instituciones de desarrollo es fundamental, especialmente en la formulación de políticas públicas efectivas, que favorezcan esta importante actividad regional.

Palabras clave: Desarrollo territorial sostenible. Sistema agroalimentario ubicado. Cachaça. 


\section{Introdução}

O ponto de partida desse estudo é o conceito de Desenvolvimento Territorial Sustentável (DTS), compreendido como um enfoque de planejamento e gestão territorial voltado à promoção de estratégias que integram as dimensões socioeconômica, sociocultural, sociopolítica e sociológica em escala local, implicando processos de recriação de identidades territoriais e a autonomia específica de cada território (VIEIRA 2006, 2009). Aglutina duas grandes correntes teóricas: a do desenvolvimento territorial (PECQUEUR, 2006) e a do ecodesenvolvimento (SACHS 1986; 2007).

A abordagem do desenvolvimento territorial, segundo Pecqueur (2005), está voltada para coordenação e envolvimento dos atores locais (produtores, governo local, trabalhadores locais e agentes de comércio), supondo um território construído, ancorado no princípio da especificação de produtos. No quadro do desenvolvimento territorial o campo teórico e empírico dos Sistemas Agroalimentares Localizados (SIAL) aparece como um novo modelo para o ambiente rural, contrapondo-se à produção estritamente capitalista. O SIAL, do ponto de vista teórico e empírico, gera inovações para compreender o funcionamento da atividade produtiva agroalimentar com apelo cultural e social, de identidade territorial, baseadas em um enfoque sistêmico (MUCHNIK et al., 2008). Destaca-se que o SIAL recobre o setor agrícola e agroalimentar por meio dos processos de especialização e de localização. O conceito e sua evolução abarcam temas como segurança alimentar, desenvolvimento sustentável, revalorização da escala territorial, proteção do meio ambiente e outros (MUCHNIK, 2012).

A problemática socioambiental tem no debate dos anos 1960 das conferências internacionais seu início, com base na percepção dos limites do crescimento econômico. Desse debate emerge o conceito de ecodesenvolvimento é concebido como um estilo de desenvolvimento adaptado às regiões rurais do terceiro Mundo (SACHS, 1986). O ecodesebvolvimento aparece como um novo estilo de desenvolvimento, voltado para valorização dos espaços regionais e locais, buscando soluções especificas para problemas particulares, com gestão dos recursos e do meio, conduzidos por um conjunto interdependente de princípios éticos (SACHS, 1986; 2007). Esse modelo está voltado à valorização dos recursos específicos de cada território e do seu melhor uso, levando em conta os dados ecológicos da mesma forma que os culturais (SACHS, 1986; 2007; VIEIRA, 2006).

Todos esses avanços teóricos foram terreno fértil para pensar as dinâmicas produtivas do Litoral do Paraná, mais especificamente da produção de cachaça ${ }^{12}$ de Morretes, um dos municípios da Microrregiao de Paranaguá - PR. Esse município está localizado próximo à região metropolitana de Curitiba, conta com uma população estimada de 16.366 habitantes (IBGE, 2018), sendo que a maioria vive na área rural (IPARDES, 2018). A cidade teve um papel relevante no desenvolvimento do estado do Paraná, nas esferas políticas e econômicas, notoriamente reconhecida

${ }^{1}$ O setor Agroalimentar congrega os segmentos de Fabricação de Produtos Alimentícios e Fabricação de Bebidas (FIESC,2018).

${ }^{2}$ De acordo com o decreto $n^{\circ} 50.972$, de 1961 , Art. $1^{\circ}$, considera-se alimento a substância ou mistura de substâncias destinadas a serem ingeridas pelo homem e a fornecerem os elementos normais ao seu desenvolvimento e conservação e incluem-se as bebidas. 
pelo Ciclo do Ouro, da Erva-Mate e da Cana de Açúcar (PREFEITURA, 2018). Morretes, a partir das últimas décadas do século passado, viu acender um grande avanço no comércio e turismo, movidos pelo reconhecimento do setor gastronômico, que coloca a culinária local e a cachaça produzida de forma artesanal em evidência (MEIRA, 2013).

A produção de cachaça de Morretes é um produto artesanal e tem sobrevivido às mudanças da sociedade contemporânea, sem perder suas características e seus traços culturais. A produção nessa região ocorre desde 0 século XVII (SEBRAE, 2017). É um produto tradicional, produzido pela agricultura familiar e tem ganhado reconhecimento internacional. Estudos demonstram que a falta de apoio institucional aos pequenos produtores tradicionais, têm promovido problemas de continuidade e de reprodução de seus conhecimentos e atividades produtivas ao longo do tempo (MEIRA, 2013). A diferenciação e a especificação são uma forma de manter essas unidades produtivas no mercado e concorrer com produtos padronizados. A partir do quadro descrito acima a questão central deste artigo é: na trajetória de evolução da produção de cachaça de Morretes como têm se organizado esses produtores, sob a perspectiva de SIAL, e quais têm sido os obstáculos à incorporação da dimensão socioambiental em tais práticas produtivas?

O artigo está estruturado em cinco seções. A primeira apresenta a problemática e introdução. A segunda apresenta a revisão de literatura ancorada nos conceitos do DTS e SIAL. A terceira seção apresenta os principais procedimentos metodológicos. A quarta seção aborda os principais resultados da pesquisa. A quinta seção destaca as considerações finais.

\section{Desenvolvimento territorial sustentável (DTS) e sistema agroalimentar localizado: inovações e possibilidades}

A concepção do desenvolvimento como simples sinônimo de crescimento econômico foi predominante até o final do século XX (VEIGA, 2006). A partir dos anos 1960 esse conceito vem sendo alargado por meio de uma série de abordagens do desenvolvimento alternativo. Vieira (2006; 2009) define que o avanço conceitual da literatura do desenvolvimento alternativo coloca em evidência o DTS. Este é considerado um enfoque de planejamento e gestão territorial centrado na promoção de estratégias que integram as dimensões socioeconômica, sociocultural, sociopolítica e socioambiental em nível local. Ele surge em um contexto onde a melhoria da qualidade de vida atuais não poderia comprometer a qualidade de vida e as necessidades das gerações futuras (SACHS, 2004; VEIGA, 2008).

Segundo Arend et al. (2019), os processos de desenvolvimento são complexos e estão sempre mudando com o passar dos anos. O DTS passa a centrarse na tentativa de aglutinar duas grandes correntes teóricas do desenvolvimento alternativo: i) a do desenvolvimento territorial (PECQUEUR, 2006; COURLET, 2006) que para Pecqueur (2006, p.12), "se caracteriza a partir da constituição de uma entidade produtiva enraizada num espaço geográfico", o território, baseado num sistema local de atores; ii) a do ecodesenvolvimento (SACHS, 1996; 2007) tendo como principal intenção definir um estilo de desenvolvimento, cujas características são: 1) esforço concentrado nas definidas ecorregião, para valorização dos seus recursos específicos e para satisfazer as necessidades ambientais dos indivíduos, 
(alimentação, saúde, etc.); 2) contribuição para as realizações do ser humano que é considerado o mais precioso recurso do processo (emprego, segurança, respeito à diversidade cultural etc.); 3) identificação, gestão e exploração de recursos naturais numa perspectiva de solidariedade, usando de forma consciente para não prejudicar as gerações futuras; 4) redução dos impactos negativos das atividades humanas sobre o meio ambiente; 5) reduzir o consumo de energia e concentrar em esforços para encontrar fontes locais de abastecimento; 6) utilização de técnicas apropriadas, as chamadas ecotécnicas com o objetivo (sociais, econômicos e ecológicos) de tornar compatíveis as estratégias do conjunto de práticas; 7) exigir uma autoridade horizontal, considerando que cada região tem suas especificidades e garantindo a participação efetiva das pessoas locais; 8) orientação e preparação nas estruturas participativas de gestão e planejamento, conscientizando as pessoas sobre a importância da natureza, sensibilizando quanto a aspectos ecológicos do desenvolvimento e à dimensão ambiental (SACHS, 1986, p.15 a 18).

Esse modelo está voltado para valorização dos recursos específicos de cada território e do seu melhor uso, levando em conta os dados ecológicos da mesma forma que os culturais, buscando promover o desenvolvimento sustentável (SACHS, 1986; 2007). Segundo Sachs (2007), para efetivação do processo de desenvolvimento sustentável, faz-se necessário considerar simultaneamente cinco dimensões: 1) sustentabilidade social; 2) sustentabilidade econômica; 3) sustentabilidade ecológica; 4) sustentabilidade espacial; 5) sustentabilidade cultural (SACHS, 2007). Somada a tal perspectiva tem-se o desenvolvimento territorial que demanda uma nova forma de pensar os sistemas de produção, visando o melhor aproveitamento dos saberes e recursos locais. Ao longo da história, o sistema territorial de atores pode aparecer de diversas formas, os estudos dos sistemas agroalimentares localizados têm apresentado importantes avanços em termos de melhor adequação das atividades rurais em zonas vulneráveis (PECQUEUR, 2006; 2005).

\subsection{Sistema agroalimentar localizado: possibilidades para inovações}

No processo de globalização, os espaços locais estão se transformando e ganhando amplitude nas esferas econômicas, políticas e culturais. Tais transformações abrem espaço oportuno para a agricultura familiar e a valorização dos produtos específicos, frente à produção em standardizada. Nessas transformações emergem novas configurações do espaço, novos atores, formas de organização para fazer frente a novos desafios e promover o desenvolvimento (GUIMARÃES et al., 2015).

De acordo com Muchnik (2006), o estudo sobre SIAL na América Latina na década de 1980 verifica a existência de aglomerados de pequenas unidades produtivas de processamento de alimentos, denominadas agroindústrias rurais (AR), como a farinha de mandioca no Brasil, a rapadura (panela) na Colômbia, os laticínios rurais no Equador, entre outros. Esses setores considerados atrasados estavam destinados a desaparecer mediante a racionalidade da economia convencional e a falta de competitividade no mercado. O cenário precisava ser convertido. Os estudos empreendidos para compreender esses setores tiraram conclusões surpreendentes, pois tais atividades sustentadas pelo saber-fazer e 
técnicas locais diferenciadas, permitiram melhorar o rendimento das economias familiares, gerar empregos, contribuir para segurança alimentar e agregar valor à produção de pequenos produtores. Na década de 1990 outras questões foram acrescentadas ao conceito como o desenvolvimento sustentável, problemas ambientais e a multifuncionalidade das zonas rurais e da agricultura (MUCHNIK, 2006).

O conceito de SIAL emerge num contexto de agravamento de problemas ambientais e alimentares em meados da década de 1990. O conceito remete à resistência, utilizando estratégias locais de desenvolvimento de recursos e produtos utilizados pelos agrupamentos geográficos das empresas agroalimentares (MUCHNIK et al., 2007). Os SIALs são definidos como:

[...] organizações de produção e serviço (unidades de produção agrícola, agroalimentares, empresas comerciais e restaurantes) associadas por suas características e funcionamento a um território específico. O meio ambiente, os produtos, os homens, suas instituições, seu saber-fazer, seus hábitos alimentares, suas redes de relacionamentos, se combinam em um território para produzir uma forma de organização agroalimentar em uma determinada escala espacial (CIRAD-SAR, 1996, p.5).

O SIAL, como base teórica e construção científica, contribui para a criação de uma abordagem agroalimentar que possa compreender o funcionamento de uma atividade produtiva de um determinado território sob a lógica sistêmica, incluindo o meio social e cultural (MUCHNIK et al., 2008). Para melhor compreender a abordagem do SIAL, Cirad-sar (1996) aponta três pontos importantes: i) não se pode entender o funcionamento e estratégias da unidade de produção, sem levar em consideração a análise da escala territorial; ii) os processos de inovação estão fortemente associados à dinâmica territorial, sendo o território um ambiente inovador e o local de construção do conhecimento. iii) arranjos institucionais, de vários tipos e em várias escalas.

O SIAL tem, assim, como estratégia a diferenciação de produtos "transportadores de identidade". Essa diferenciação não está ligada somente ao conhecimento, produção e técnicas especificamente agrícola, mas também ao ato de consumir e comprar os produtos alimentares (CIRAD-SAR, 1996). A origem territorial do produto é um indicador de qualidade, a proximidade criada com o consumidor que geralmente conhece ou já ouviu falar do processo produtivo gera um valor simbólico, determinante para valorização do produto e avaliação da qualidade (REQUIER-DESJARDINS et al., 2006). Os vínculos com os consumidores são elementos constitutivos desse tipo de conhecimento, ligados a fatores culturais e regionais dos produtos agrícolas consumidos (REQUIER-DESJARDINS et al., 2006). Outras características podem ser incorporadas na questão da qualidade como a paisagem rural e a gestão ambiental.

Dessa forma, o SIAL parece estar inserido numa rede dupla: a) no nível horizontal territorial, naquela formada por atividades rurais agrícolas e não agrícolas, instituições locais, know-how local etc; e b) no nível vertical, à jusante da cadeia produtiva, naquela formada por atividades de comercialização, embalagem, marketing e consumo. Esses dois conjuntos de relações não são independentes quando se trata da relação de qualidade e tipicidade de produtos. Isto na medida em que esta última 
baseia-se freqüentemente não só nas características do processo de produção agrícola, mas também nas características culturais ou ambientais do território rural (REQUIER-DESJARDINS et al., 2006 p.125).

Muchnik (2006) aponta três noções centrais para a compreensão do SIAL: a) noção de território construído, onde as relações econômicas não se baseiam somente nas leis de mercado, onde o processo de territorialização é considerado como material e cultural e os atores transformam esses espaços dando sentido a suas vidas na sociedade; b) a noção de referência identitária, guiadas pelo sentimento de territorialidade e que aparecem em dois níveis, direções sociais (religião, idioma, origem etc) e direções individuais (nome, sobrenome, comércio); c) a alimentação como fator social, que diferencia a noção de SIAL e SPL onde o primeiro tem como especificidade os bens alimentares, que trazendo diferentes variáveis: a saúde de quem consome, a composição e características dos alimentos, a identidade cultural, a dinâmica territorial, etc.

Muchnik (2006) define uma metodologia para análise de um SIAL, baseado em quatro dimensões: a) dimensão histórica, onde o processo de formação das experiências de campo estudadas podem ser apreciadas; b) dimensão técnica, centrada nas observações, percepções e análise do saber-fazer e das técnicas utilizadas, relacionado aos produtos agroalimentares, com identidade simbólica; c) dimensão alimentícia, tendo como foco as relações sociais, culturais e econômicas, entre o produto e o consumidor; d) dimensão institucional, posicionado no SIAL, levando em consideração as relações entre os atores sociais, suas estratégias coletivas e individuais. Essas dimensões servem de alicerces para aproximar a noção de SIAL do ponto de vista teórico e empírico (AMBROSINI, et al., 2008).

Para fins deste trabalho, é relevante entender o território como promotor de uma visão diferenciada para as questões espaciais, a base da construção coletiva e interação entre os atores. Acrescenta Pecqueur (2006) que é relevante compreender a economia dos territórios que possuem características próprias, sendo elas: i) o equilíbrio da sociedade e comunidade, tendo em relevância as relações sociais e noção de ancoragem territorial, diferente da economia padrão fordista onde o mercado é centrado nele próprio; ii) há construção de um capital cognitivo coletivo, resgatando a história local e a memória coletiva no funcionamento e na organização do sistema produtivo onde a aprendizagem dos grupos é valorizada e compartilhada; iii) a reciprocidade está presente no âmbito territorial, baseada na amizade, gratidão e está enraizada na identidade social dos atores econômicos.

\section{Aspectos metodológicos}

O estudo é do tipo empírico, orientado a partir de um arcabouço teórico. A pesquisa é pautada em uma abordagem predominantemente qualitativa, pois possibilita analisar em profundidade o fenômeno pesquisado. Porém, não se isentou da incorporação de dados quantitativos. É um estudo descritivo (CERVO et al., 2007).

A coleta de dados foi organizada em dados primários e secundários. Os dados primários foram obtidos junto a entrevistas semiestruturadas. Para construção do roteiro de entrevistas foi levado em consideração os dados obtidos 
na fase exploratória, bem como a matriz teórico-metodológica baseada no referencial teórico e que contempla a metodologia proposta por Muchnik (2006), para análise de um SIAL, dirigidos pelas dimensões: a) histórica; b) técnica; c) institucional, e d) alimentícia. Para seleção dos atores chave pesquisados foi utilizada a técnica de coleta de dados denominada snowball (bola de neve). Tal técnica vale-se, primeiramente, de o pesquisador especificar as caraterísticas dos membros da amostragem, depois seleciona-se uma pessoa ou um grupo que possua essas características, na sequência apresenta-se a proposta de estudo, registra-se os dados e por último solicita-se aos entrevistados indicações de pessoa(s), pertencentes a população-alvo da pesquisa (OSTA, 2018). Por meio dessa técnica, obteve-se os seguintes participantes da pesquisa: representantes dos produtores de cachaça, representantes de instituições de apoio (ADETUR, SEBRAE), representantes do poder público local (Secretaria de Agricultura e secretaria de turismo), representantes dos cidadãos do município, especialistas, totalizando 11entrevistados. Foram entrevistados nesse estudo seis produtores, sendo três formais e três informais. Foi realizada, também, uma entrevista com um antigo produtor.

Os dados secundários foram obtidos por meio de documentos dos arquivos históricos locais, bem como dados obtidos nas bases de dados do Instituto Paranaense de Desenvolvimento Econômico e Social (IPARDES), Instituto Brasileiro de Geografia e Estatística (IBGE), Relação Anual de Informações Sociais (RAIS), etc. A partir da matriz teórico-metodológica a seguir (Quadro 1) apresentam-se os principais conceitos, componentes, autores e instrumentos de coleta e análise dos dados:

Quadro 1: Matriz teórica da pesquisa

\begin{tabular}{|c|c|c|c|c|}
\hline CONCEITO & COMPONENTES & $\begin{array}{l}\text { COLETA DE } \\
\text { DADOS }\end{array}$ & $\begin{array}{l}\text { ANÁLISE DOS } \\
\text { DADOS }\end{array}$ & AUTORES \\
\hline $\begin{array}{l}\text { Caracterizaçãa } \\
\text { o do } \\
\text { Território e } \\
\text { da produção } \\
\text { de cachaça }\end{array}$ & $\begin{array}{l}\text { - Território dado } \\
\text { - Território construído } \\
\text {-Número de produtores } \\
\text { e perfil }\end{array}$ & $\begin{array}{l}\text { - } 8 \text { Entrevistas } \\
\text { - Documentos }\end{array}$ & $\begin{array}{l}\text { Análise descritiva } \\
\text { Análise de } \\
\text { documentos } \\
\text { históricos } \\
\text { Análise de } \\
\text { Conteúdo }\end{array}$ & $\begin{array}{l}\text { Muchnik } \\
\text { (2006);Pecqueur } \\
\text { (2005). }\end{array}$ \\
\hline $\begin{array}{l}\text { Sistema } \\
\text { Agroalimenta } \\
\text { r Localizado }\end{array}$ & $\begin{array}{l}\text { - Instituições de apoio e } \\
\text { perfil } \\
\text { - Dimensões histórica, } \\
\text { técnica, institucional, } \\
\text { alimentícia } \\
\text { - Grau de articulação } \\
\text {-Relação com o turismo }\end{array}$ & $\begin{array}{l}\text { - } 11 \text { Entrevistas } \\
\text { - Documentos } \\
\text {-Estatísticas } \\
\text { locais }\end{array}$ & $\begin{array}{l}\text { Análise de conteúdo } \\
\text { Análise descritiva }\end{array}$ & $\begin{array}{l}\text { Guimarães et al. } \\
\text { (2015); Muchnik, } \\
\text { 2012; Muchnik et } \\
\text { al. (2007); } \\
\text { Pecqueur (2001). }\end{array}$ \\
\hline DTS & $\begin{array}{l}\text { - Consequências da } \\
\text { produção da cachaça } \\
\text { sobre os recursos } \\
\text { naturais }\end{array}$ & $\begin{array}{l}\text { - } 11 \text { Entrevistas } \\
\text { - Documentos }\end{array}$ & Análise de conteúdo & $\begin{array}{l}\text { Veiga (2006); } \\
\text { Menezes (2009); } \\
\text { Pecqueur } \\
\text { (2005);Sachs } \\
(2006) .\end{array}$ \\
\hline
\end{tabular}

Fonte: Curvelo (2019, p. 24). 
A análise dos dados deu-se por meio do uso da análise de conteúdo. De acordo com Bardin (1977) essa técnica visa extrair informações e categorias analíticas presentes nas falas dos sujeitos de pesquisa, dividindo-se em três fases: a) pré-análise: desenvolvida para operacionalizar e sistematizar as primeiras ideias no planejamento da análise com um a intenção de desenvolver as próximas operações; b) a exploração do material: configura a administração sistêmica das decisões tomadas, para essa fase é necessário que a anterior tenha sido concluída, parte mais duradoura e é um processo de longo prazo, desafiador onde são feitos os registros e recortes, consiste essencialmente de operações de codificação (BARDIN, 1977); c) resultados, a inferência e a interpretação, nessa fase consiste em coletar os achados de pesquisa de todo o material coletado (documentos, entrevistas e documentações), buscando responder os objetivos iniciais e promover 0 conhecimento científico sobre o tema da pesquisa (BARDIN, 1977).

\section{Sistema agroalimentar localizado: trajetória, dimensões e inovações na produção de cachaça de Morretes rumo ao DTS}

O território pesquisado faz parte da microrregião de Paranaguá e abriga grande porcentagem da avifauna e da mastofaunda do Paraná. Essa região contém 98 quilômetros de praia, constituído de um ecossistema diverso e rico, permitindo diversas opções de ocupação e uso do solo (LEAL, 2000). Nela há, também, um vasto patrimônio cultural, natural e histórico, destacando as cidades de Antonina, Morretes e Guaraqueçaba, cidades históricas que possuem importantes monumentos (LEAL, 2000). As principias atividades econômicas são: agropecuária, turismo praiano e atividade portuária (ESTADES, 2003). No que se refere aos aspectos ambientais, Morretes tem mais de 50\% do território coberto por Unidades de Conservação - UCs e/ou áreas protegidas (DENARDIN et al., 2008).

O Litoral paranaense começou a ser povoado por volta de 1550, por portugueses e espanhóis que vieram em busca de ouro. Diante das especificidades naturais pode-se separar a região em três grupos de municípios: "[...] os portuários (Paranaguá e Antonina); os rurais (Morretes e Guaraqueçaba); e os praianoturísticos (Guaratuba, Matinhos e Pontal do Paraná)" (ESTADES, 2003 p.26).

A maioria dos primeiros habitantes de Morretes eram de descendência portuguesa, os quais foram se misturando com grupos de índios que encontraram na região, "[...] as terras foram ocupadas lentamente pelos descendentes desse primeiro grupo e por imigrantes que vieram do século passado" (CAVAGNOLLI, 1995 p.76). O município também sofreu influência de povos vindos da Itália, Espanha e Alemanha.

A produção de cachaça de Morretes existe desde o século XVIII desde a construção dos primeiros engenhos e do engenho central criado em 1877. Muitos colonos italianos que plantavam grandes quantidades de cana alegavam que o frete e o baixo preço oferecido pelo engenho central diminuía o lucro, sendo mais vantajoso construir novos engenhos. Desta forma, alguns imigrantes com razoável poder aquisitivo construíam seus próprios engenhos (BORGES, 1990). A agricultura de cana de açúcar era próspera naquela época e os engenhos foram se multiplicando na região. Com o falecimento dos primeiros dirigentes do engenho central a atividade deste foi decaindo, passando de mão em mão (BORGES, 1990). 
A produção de cachaça passou por inúmeras transformações nas últimas décadas. Tais mudanças alteraram as condições de concorrência e competitividade, fazendo com que o número de alambiques tenha reduzido drasticamente desde a consolidação da produção em Morretes. A produção de cachaça cresceu muito até aproximadamente os anos de 1950, com cerca de 60 engenhos, mas com as dificuldades em função da falta de capital para manter os engenhos, após uma forte fiscalização do ministério da agricultura em 1958, esses foram fechando.

Quanto a dimensão histórica verifica-se que há, no contexto da produção de cachaça, referências identitárias, guiadas pelo sentimento de territorialidade, seja ela na origem, nome e sobrenome dos entrevistados, assim como na relação de confiança, cooperação, aprendizagem (MUCHNIK, 2006; SIQUEIRA, 2016). A produção de cachaça de Morretes é de origem familiar, todos os pesquisados destacam que trabalham com a família na produção. A maioria dos produtores entrevistados nasceram no município de Morretes. Destaca-se para o fato de que os produtores entrevistados aprenderam o ofício da produção de cachaça com seus antepassados. Os engenhos foram montados pelos familiares e os conhecimentos foram passados de geração em geração. Na perspectiva da territorialidade a produção de cachaça de Morretes tem vínculo inter-geracional e sentimento de pertencimento local, pois conta a história do território, que é construído com base emocional e afetiva, consagrando o saber-fazer regional, com um produto difenciado (MUCHNIK, 2006; DRUMM, 2018). A tradição está presente historicamente na produção da cachaça de Morretes, devido a continuidade da atividade passada de geração em geração e no desejo dos produtores de que seus filhos ou parentes continuassem a produzir cachaça na região.

A sucessão familiar é outro fator importante no meio rural, quando ela não acontece, perdem-se conhecimentos tácitos, que poderiam contribuir para a consolidação de um SIAL (SPECHT, 2009). Observa-se que há o compartilhamento da experiência histórica e da identidade local do território pesquisado e no âmbito da produção de cachaça (REQUIER- DESJARDIN et al., 2006, p. 123). Embora perceba-se uma grande preocupação dos produtores em relação às exigências do mercado atual, a produção de cachaça de Morretes manteve suas características originais e o processo produtivo ensinado por seus antepassados.

As especificidades da produção de cachaça de Morretes encontram-se desde o preparo do solo, sem uso de agrotóxicos ou adubos químicos, dentro dos padrões de produção orgânica, cercada pela mata nativa (PORTO MORRETES, 2019). Os produtores de cachaça de Morretes não queimam a palha da cana-de-açúcar, prática considerada como causadora de fortes impactos ambientais. A cana-deaçúcar é colhida manualmente e cuidadosamente selecionada (PORTO MORRETES, 2019). A cana-de-açúcar cultivada em Morretes é única e especial devido as características marcantes do clima quente e úmido, que sofre influência da Serra do mar e o fermento usado, denominado caipira, não faz adição de elementos químicos. Assim, a cachaça de Morretes caracteriza-se como orgânica (PORTO MORRETES, 2019).

A produção de cachaça de Morretes abrange os dois distritos do município: Morretes e Porto de Cima. Há cerca de 12 produtores de cachaça sendo quatro formais e oito informais, produtores que não possuem registros no Ministério da Agricultura, Pecuária e Abastecimento - MAPA, órgão responsável pela fiscalização 
dos estabelecimentos. Desta forma, a formalização da maioria dos engenhos, acontece apenas na esfera municipal, com pagamento de taxas referentes à vigilância sanitária e alvará, com intuito de evitar transtornos com a fiscalização local. Existem, em menor número, ainda, aqueles que não possuem nem a formalização municipal.

De acordo com Meira (2013), os pequenos produtores geram cerca de cinco mil litros anuais, enquanto os grandes produtores produzem em torno de 50 a 100 mil litros por ano. Essa quantidade varia de acordo com os meses do ano, dependendo da qualidade da cana cultivada e época colhida. Segundo Anacleto et al. (2014, p. 97), “[...] a produção atual de aguardente artesanal na região é em média $40 \%$ menor que a registrada na década passada, que revelou que a produção da aguardente no litoral do Paraná se encontra em declínio".

O número de propriedades com cultivo de cana-de-açúcar reduziu drasticamente. De acordo com Ipardes (2018) há cultivo de cana-de-açúcar em 130 hectares, mas na época do engenho central chegou a ter mais de mil hectares. Essa diminuição foi causada pelo aumento da concorrência, principalmente vinda de outros estados do Brasil,além da falta de apoio governamental há pouca articulação coletiva dos produtores e muitas exigências dos órgãos fiscalizadores (KNOPIK e FLEIG, 2009).

Uma parcela dos produtores, principalmente os formalizados, sempre estão se atualizando, com técnicas diferenciadas e inovações, demonstrando preocupação com o futuro dessa atividade produtiva. Os produtores que trabalham na informalidade gostariam de se regularizar, mas alegam que não possuem capital. Apenas quatro produtores são formais na região. O motivo para a não formalização da produção está na dificuldade de atender às demandas burocráticas do estado. Muitos desses produtores não têm conhecimento das reais necessidades legais para poderem atuar. Esse é um problema compartilhado pelos muitos pequenos produtores rurais do Brasil, bem como pelos micros e pequenos empreendedores em geral (MENEZES, 2009).

As demandas burocráticas, os impostos e demais formalidades se impõem como entrave a maior parte dos produtores de cachaça de Morretes, gerando entre os produtores segregação e distanciamentos entre aqueles que conseguem se manter na formalidade, cumprindo as obrigações legais e aqueles que não conseguem. Esse, portanto, é um dos entraves à cooperação entre os produtores de cachaça de Morretes. Quanto a mão-de-obra que atende ao mercado de trabalho da atividade da produção de cachaça, percebe-se que ela é oriunda da própria região. Observa-se, que em média, trabalham na produção de cachaça cerca de cinco pessoas entre familiares e empregados. Três entrevistados ainda contratam empregados (fixos) para ajudar na produção, mas há também a contratação de trabalhadores temporários no período de safra, que começa em junho de cada ano e dura em média 6 meses.

\subsubsection{As dimensões institucional, técnica e alimentícia: perspectivas para inovação}

Para a avaliação da categoria institucional é preciso reconhecer os atores locais e suas estratégias, bem como a influência do Estado. Os principais atores da produção de cachaça de Morretes são produtores, consumidores, órgãos públicos 
locais e estaduais, instituições de apoio. No quadro geral de tais instituições de apoio existentes na região tem-se: i) SEBRAE, “[...] apoia as decisões dos empresários, dos potenciais empresários e dos potenciais empreendedores, no campo e na cidade é a instituição que entende de pequenos negócios e possui a maior rede de atendimento do País" (SEBRAE, 2017); ii) Prefeitura municipal de Morretes, sede do poder executivo do munícipio,; iii) ADETUR, “[...] que é uma entidade privada sem fins lucrativos que representa o trade turístico do litoral do Paraná" (ADETUR, 2019) e iv) EMATER - PR, a qual sua missão é, “[...] promover o desenvolvimento Rural Sustentável, coordenando, articulando e executando Assistência Técnica e Extensão Rural em benefício da sociedade paranaense" (EMATER, 2019). Percebe-se uma insatisfação por parte dos produtores de cachaça de Morretes em relação as instituições de apoio e aos aspectos econômicos e políticos locais.

Verifica-se que não existem linhas de crétidos adequadas para o setor. $O$ custo financeiro para adequação às normas e para a formalização da atividade é elevado. Há necessidade de serem realizadas melhorias e adaptações nas estruturas físicas dos alambiques, para que atendam a todas as exigências feitas pela vigilância sanitária e pelo MAPA - Ministério da Agricultura, Pecuária e Abastecimento.

A carga tributária é considerada elevada por grande parte dos entrevistados, evidenciando o problema da não diferenciação entre padrões de regulamentação dos produtos artesanais e dos industriais. Sem o apoio do governo, por meio da EMATER e SEBRAE, os produtores com inadequações junto aos órgãos responsáveis não conseguirão se adequar às normas (ANACLETO et al., 2014). Tal perspectiva é corrobora pela fala "[... ] Tributário, esse é o maior problema, a não distinção entre produto artesanal e produto industrial (P2, 51 anos)".

Outras dificuldades dos agricultores são a obtenção de autorização para produzir em maior quantidade a cana-de-açúcar, pois a região é cercada de unidades de conservação. Essa é uma questão controversa, mas que merece ser debatida. Por um lado, a preservação do meio ambiente local tem colocado em xeque algumas iniciativas de produção, ainda que artesanais. Por outro lado, é preciso reconhecer se essas atividades comprometem a reprodução dos ecossistemas locais necessários a manutenção da vida. Faz-se necessário mais estudos e pesquisas que comprovam que tais atividades podem impactar os ecossistemas locais e o tamanho desse impacto.

\footnotetext{
A região é a região de maior preservação, nós não temos desenvolvimento nenhum dentro do nosso setor, nenhum setor na verdade no Litoral do Paraná tem desenvolvimento, tudo é proibido de fazer, aliás nós tivemos um grande retrocesso, é o único estado da federação que tem o COLIT, que trabalha com o intuito de preservar, mas ele trabalha pra preservar sem pagar a conta pra quem habita. Eu sou favorável a permanência da Mata Atlântica, porém desde que a sociedade do Paraná e do Brasil pague essa conta pro caiçara [...] não é possível que a gente queira continuar querendo preservar da forma que está sendo preservada com a miséria dessa sociedade ( $\mathrm{P} 1,62$ anos).
}

Os produtores necessitam de suporte para reconhecer o potencial da preservação do meio ambiente local no sentido de promover maior articulação com o turismo. Observa-se a existência de conflitos com os órgãos fiscalizadores, com 
pouco esclarecimento sobre as potencialidades dos espaços naturais existentes no município.

A pesquisa de campo também demonstrou que a infraestrutura local não vem melhorando (transporte, comunicação, serviços de saúde e educação, etc.). 0 que não tem contribuído para melhoria das condições de produção da cachaça, das condições de vida das pessoas que trabalham na sua produção e na facilidade de acesso dos turistas para o escoamento da produção local. Os produtores de cachaça não têm poder para exercer influência em prol da melhoria das condições de vida e de formas de distribuição e logística dos produtos. Os engenhos "[...] acabam não sendo visibilizados, nem contemplados satisfatoriamente pelas políticas públicas de turistificação da cidade" (MEIRA, 2013 p.89).

A cachaça tem uma representatividade pequena na economia da região, os entrevistados destacam que a produção já gerou mais trabalho e renda no município. Todavia, reconhecem o potencial do produto que possui notoriedade. A atividade poderia se alinhar com outros segmentos da economia regional, particularmente com o turismo, atraindo visitantes para a cidade de Morretes. Alguns alambiques possuem lojas próprias e pousadas, sendo pontos de referência turística. Reconhece-se que essa atividade pode também exercer a fixação do agricultor no campo, pois a produção de cana é intensiva em mão-de-obra.

Dentre as instituições que podem apoiar o setor, na percepção dos entrevistados, são a EMATER, a Embrapa (Empresa Brasileira de Pesquisa Agropecuária), as agências de fomento estaduais (Fomento Paraná, por exemplo) e o SEBRAE, etc. O fomento de crédito aos produtores ainda é pequeno. Os produtores pesquisados utilizam recursos próprios e familiares na manutenção e capital de giro, compra de equipamentos, insumos, dentre outros materiais necessários à manutenção dos seus engenhos. Destacam que não existem linhas de créditos adequadas para as necessidades dos produtores. Apenas dois dos entrevistados utilizaram crédito ofertado pelo Programa Nacional de Fortalecimento da Agricultura Familiar (PRONAF) e outras instituições atuantes no ramo. O acesso ao crédito é um ponto frágil para a organização produtiva pesquisada, um elemento essencial à promoção de um SIAL e à inovação (MUCHNIK, 2006; PECQUEUR, 2005; SCHUMPETER, 1982).

Cabe ressaltar ainda outra instituição que tem cooperado com os produtores de cachaça de Morretes, a Universidade Federal do Paraná. A instituição vem realizando estudos com as variedades de cana, por meio de experimentos em épocas esporádicas.

$\mathrm{Na}$ dimensão técnica remete-se às características relacionados ao uso de recursos naturais tanto na produção de cana-de-açúcar, como no processo de agroindustrialização, assim como técnicas e instrumentos de fabricação da cachaça (DENARDIN et al., 2015). São diversas as variedades de cachaças produzidas pelos produtores: cachaça branca, amarela, envelhecida, clássica, premium, extrapremium, ouro, prata etc., mas todas se originam da cachaça branca. Foram realizados diversos estudos com diferentes canas. A cana que mais se adaptou ao solo e ao clima da região é a havaianinha. O solo e o clima da região favorecem o plantio da cana-de-açúcar. O calor, a umidade, o regime de chuva e a quantidade de sol característicos do município de Morretes colocam a cachaça da região em uma posição única, esse é denominado micro-clima, influenciado pela Serra do Mar 
(PORTO MORRETES, 2019). Para Pecqueur (2006) essas são características essenciais para se identificar recursos e ativos específicos do território. Fica evidente que o clima de Morretes constitui um ativo específico, pois garante a produção em todos os meses do ano, bem como contribui para que a cachaça tenha um envelhecimento específico. O processo produtivo e a cana-de-açúcar da região proporcionam uma cachaça com pureza, aroma e acidez diferenciada (SEBRAE, 2017).

Quando questinados se existiam práticas e know how específicos na produção da cachaça de Morretes os entrevistados destacaram que o tipo de fermento (caipira) usado na produção é, também, um diferencial. A cachaça produzida em Morretes é totalmente artesanal. Quanto às técnicas existentes na produção da cachaça os entrevistados destacaram que elas têm diferenciais de produtor para produtor e que estas advêm dos conhecimentos repassados pelos seus antepassados, "[...] esse é um saber do pessoal do município né, porque quem mexe com cachaça sempre teve seus antepassados né" (P3, 62 anos). "[...] Não é só nosso mesmo, isso aí é de origem daqui, são saber fazer do município” (P6, 53 anos).

Segundo Denardin et al. (2015, p. 215) esses são saberes "[...] que não se encontram em nenhum manual, saberes que não são repassados por técnicos, no entanto cada agricultor tem sua receita, sua lógica, sua racionalidade". Os engenhos de cachaça de Morretes caracterizam-se por serem agroindústrias que produzem cachaça para comercialização. Os saberes locais e os valores identitários são compartilhados em relação às trocas culturais, técnicas de plantio e colheita, variedades de cana, rendimento da cachaça e qualidade do fermento usado pelos produtores.

Existe um grau de amizade e não parentesco entre os produtores. No decorrer da história da produção de cachaça os produtores se reuniam com mais frequência para conversar sobre a produção de cachaça e melhorias em geral. Nos últimos quatro anos essas reuniões não vêm acontecendo, conforme entrevistas, exceto para aqueles que participam do processo de IG, que participam de encontros realizados pelo SEBRAE. Em eventos ocasionais, como a Festa Feira ${ }^{3}$, os mesmos trocam informações sobre o produto e processo produtivo. Todos relataram que a troca de informação com a comunidade local acontece nesses eventos.

Um aspecto relevante a ser considerado na dimensão técnica é que o saber fazer da produção de cachaça tem forte relação com a história e a cultura da região de Morretes, construída por seus antepassados e fruto dos relacionamentos com os atores, por meio de vínculos informais e formais de reciprocidade. A atividade produtiva da cachaça está baseada em relações sociais enraizadas. Os recursos específicos são produzidos a partir de uma troca que não a mercantil, movida pela reciprocidade, intrínseca à cultura e aos costumes do espaço geográfico próximo (PECQUEUR, 2005; CAZELLA et al, 2019). Esses vínculos não acontecem em todo o território, existe segregação entre os produtores formais e informais, ainda a cooperação e reciprocidade se realizam somente pelos alambiques com maior proximidade geográfica. Apesar das relações estabelecidas entre os produtores

\footnotetext{
${ }^{3}$ Feira anual realizada em Morretes que objetiva de divulgar e promover o artesanato e a agricultura local (PREFEITURA, 2018).
} 
dessa atividade ter certo grau de confiança (proximidade, conhecimento pessoal, convívio, acordos informais etc.), considera-se que esses vínculos são ainda fracos e acontecem esporadicamente, baseado em interesses comerciais (mercado).

Cada alambique tem suas especificidades, uns produzem cachaça de banana, outros envelhecem em barricas de carvalho por um certo período de tempo, outros só vendem cachaça branca e amarela. A pesquisa demonstrou que a maioria dos entrevistados utilizam alambiques de cobre para destilação e o fermento que é usado na produção é natural, itens obrigatórios para caracterizar o produto como artesanal. Tal fato coloca a cachaça de Morretes distante da lógica de padronização usada por grandes empresas. Essas especificidades são aspectos relevantes na caracterização de um SIAL. Nesse tipo de organização produtiva os consumidores reconhecem e valorizam o produto associado à know-how, organizações produtivas e territórios (CIRAD-SAR, 1996).

No que se refere à dimensão alimentícia que tem como foco as relações sociais, culturais e econômicas entre os produtos e o consumidor (MUCHNIK, 2006; SPECHT, 2009), demonstra que o diferencial da cachaça de Morretes é a qualidade do produto, as técnicas de destilação e o processo produtivo artesanal. As cachaças produzidas em alambiques de Morretes foram premiadas internacionalmente, reconhecidas como as melhores cachaças do Brasil. Observa-se que a oferta de cachaça local não consegue atender a demanda e o mercado consumidor. A produção é pequena, sendo um dos problemas a falta de matéria-prima, a cana de açúcar. Em algumas situações a falta da matéria-prima impõe à necessidade de algumas estratégias alternativas como o fato de que os produtores tomam emprestado de seus vizinhos, devolvendo quando o estoque é reposto. Ou, ainda, combinam com o comprador a data da entrega de acordo com a capacidade de produção.

O entrevistado P.2 (51 anos), acredita que a estratégia mais efetiva para suprir a demanda seria conseguir que a legislação tributária atual fosse modificada no sentido de promover alíquotas diferenciadas para produtos artesanais. Todavia, alguns entrevistados consideram que o fato de produzirem em menor quantidade é uma vantagem e não uma desvantagem, pois a cachaça de Morretes é um produto específico da região, podendo ser agregado valor ao produto por sua qualidade. $O$ preço seria mais elevado em função da escassez e qualidade. Essa é uma concepção destacada pela literatura da área que define a renda de qualidade territorial, em que o consumidor está disposto a pagar mais caro por um produto específico do território (DENARDIN et al., 2015; PECQUEUR, 2006).

Quanto às estratégias de comercialização alguns produtores formais têm lojas próprias e até e-commerce. Outros contam com representantes e atendimento diferenciado para os clientes, distribuição terceirizada ou realizada por veículos próprios. Os produtores informais atendem seus clientes nos seus respectivos alambiques e, são os próprios clientes, responsáveis pelo transporte. Segundo Anacleto et al. (2014) a ausência de consciência dos gestores da situação de mercado (passividade comercial) está associada a fase de declínio da produção de cachaça na região.

Destaca-se, também, que a cachaça de Morretes é facilmente encontrada em restaurantes, barracas, bancas, comércio de beira de estrada, mercados, feiras etc. na região do litoral do Paraná. No entanto, os maiores compradores são os 
apreciadores de cachaça, que fazem questão de buscar o produto no território. $\mathrm{O}$ maior mercado consumidor é local e regional. Todavia, muitos produtores estão ganhando espaço no mercado internacional em função das premiações, o que poderá abrir espaço para um novo público de consumidores.

O mercado concorrente é inexistente conforme os produtores pesquisados. Em contrapartida, argumentaram que Minas Gerais e os produtos de baixa qualidade e baixo custo são concorrentes da cachaça de Morretes. Percebeu-se, também, que há concorrência entre os próprios produtores locais, mas um tipo de concorrência menos agressiva.

Quanto ao futuro da cachaça de Morretes em termos de mercado consumidor e concorrente os produtores legalizados entrevistados enxergam um futuro promissor, com crescimento exponencial. Todavia, aqueles que trabalham na informalidade acreditam que a cachaça de Morretes não irá prosperar, com preocupação de extinção dos pequenos produtores. Tais entrevistados apontam que para evitar essa extinção será necessária a formulação de políticas públicas que favoreçam os produtores artesanais com linhas de crédito favoráveis, com juros mais baixos, e diminuição da carga tributária.

Os produtores formais, vendem a cachaça etiquetada, rotulada e registrada. Os produtores informais têm menos instrumentos de comercialização, alguns etiquetam ou possuem rótulo, mas a grande maioria vende sem identificação em tonéis. Os representantes da prefeitura informaram que a instituição não acompanha a comercialização da cachaça de Morretes, desde a produção até o consumidor final. O SEBRAE não apoia em todo o processo, mas abre mercados, por meio de rodadas de negócios, feiras, busca de novos clientes etc:

Existe pouca sinergia e parceria entre os produtores, o que demonstra a necessidade de maior organização dos produtores para conquistarem novos mercados. Nesse sentido, há déficits em termos de ação coletiva. Há necessidade de práticas "[...] que visem à solidariedade, à cooperação e incentivem a confiança entre os atores devem ser priorizadas" (DENARDIN, 2016, p.68). A questão cultural é muito presente em torno da tradição da produção de cachaça de Morretes. Há necessidade de cuidado com os riscos da elitização e com o processo de industrialização, algo percebido em outros estudos de outras culturas como o que retrataram Santos e Diesel (2020). É importante garantir a existência dos pequenos produtores tradicionais, fomentando a cultura e promovendo o desenvolvimento territorial.

\subsubsection{A sustentabilidade e a produção de cachaça de Morretes}

Esse estudo tem uma preocupação ampla com o conceito de sustentabilidade. Para tanto, toma-se como base os diferentes tipos de sustentabiliade: a social, a econômica, a espacial, a cultural e a ecológica (SACHS, 2007). Quanto a sustentabilidade social que refere-se a um processo de desenvolvimento mais equilibrado, com igualdade na distribuição de renda e bens, distanciando os padrões de qualidade de vida dos ricos e dos pobres (SACHS, 2007) verifica-se que o surgimento da produção de cachaça e a forma de produção, os primeiros habitantes, em sua grande maioria eram de origem portuguesa, que se misturaram com indígenas que viviam na região (CAVAGNOLLI, 1995). O ano de 1733 foi marcado pelo primeiro registro de produção de cachaça na região. Somente com 
a chegada dos imigrantes italianos essa produção se intensificou, decorrente da construção do engenho central e dinamização da produção (BORGES, 1990). O processo produtivo é herdado dos antepassados dos produtores de cachaça de Morretes e teve pouca ou nenhuma alteração. O saber-fazer e as técnicas usadas na produção estão presentes em todo processo produtivo, características específicas da cachaça de Morretes.

Na sustentabilidade econômica tem-se relação com a dimensão institucional do SIAL. Verificou-se que apesar da produção de cachaça ter importante papel no resgate cultural e como atividade que gera trabalho e renda, não há políticas públicas efetivas voltadas a essa atividade. O setor público é pouco atuante e não tem apoiado os produtores de cachaça de Morretes. Cada produtor tem estratégias individuais para permanecer no mercado, nesse caso é importante destacar o papel do SEBRAE como organização da sociedade civil que tem contribuído para com a produção de cachaça de Morretes, auxiliando os produtores a alcançarem novos mercados.

A sustentabilidade espacial está relacionada com as dimensões institucional e técnica do SIAL, com aspectos de articulação das várias instituições acerca de ações voltadas para fixação das famílias no campo. Fica evidente que os produtores de cachaça de Morretes que são mais próximos entre si são aqueles que mais cooperam. A sustentabilidade espacial também relaciona-se com as dimensões histórica e alimentícia no que se refere ao produto específico do território, cujo clima e solo da região proporcionam uma condição de especificidade. O que tem garantido a sobrevivência e fixação da população rural, que por meio da qualidade e potencial competitivo do produto torna-o mais resistente, frente a produção em larga escala dos grandes centros urbanos.

Acerca da sustentabilidade cultural ela está relacionada com as dimensões históricas, técnicas e alimentícias do SIAL que tem relação com a tradição e o saber fazer, passado de geração em geração. No caso pesquisado, a produção de cachaça está relacionada a tradição de alguns povos que foram pioneiros no território como as famílias Scucatos, Malucelli de origem italiana e Freitas de origem portuguesa. Esses saberes locais quando articulados com processos de inovação e qualidade específica do produto territorial, segundo Pecqueur (2005), são características primordiais do SIAL.

Por fim, a sustentabilidade ecológica está relacionada à dimensão técnica do SIAL. Chamadas de laços materiais por Muchunik (2006) são as técnicas produtivas, juntamente com as características do produto, clima, solo etc., a forma de relacionamento do homem com o meio ambiente. Observou-se que apenas um produtor relatou possuir painéis solares de captação de energia, o que caracteriza uma técnica mais sustentável. Todos os produtores informaram que fazem o reaproveitamento da água. Os dejetos da produção são aproveitados na lavoura e no processo de produção da cachaça. Os produtores relataram que não existem problemas nos seus alambiques e nas atividades relacionadas ao setor ligados à poluição e degradação ambiental. Relatam ainda que tudo dentro dessa atividade é reaproveitado e fiscalizado pelos orgãos competentes.

Dentre os recursos naturais mais utilizados tem-se a água e o solo. Estudo realizado por Filho (2008), com dez propriedades de Morretes, onde se cultivava cana-de-açúcar e se produzia cachaça, demonstrou que apenas uma propriedade 
utilizava adubo formulado, oito utilizavam adubos de origem animal e/ou vegetal (esterco, bagaço e vinhoto) e uma propriedade não utilizava nenhum tipo de adubo. Observou-se que quatro propriedades utilizavam produtos químicos, como o herbicida glisofato no controle de plantas daninhas e, em outras seis, esse controle era feito manualmente, sem a utilização de tais químicos. Dos dez sistemas analisados por Filho (2008, p. 48), concluiu que, "seis podem ser considerados orgânicos, onde a adubação, quando utilizada, provêm de fontes orgânicas (vegetais/animais) e o controle das plantas daninhas é baseada no controle manual através de capinas e roçadas". Nesse contexto, conforme Knopik e Fleig (2009), a produção de cachaça de Morretes, pode ser caracterizada como orgânica, pela baixa quantidade de resíduos químicos utilizados no cultivo da cana-de-açúcar em Morretes.

\section{Considerações finais}

A produção de cachaça em Morretes existe desde o século XVIII, sendo que seu primeiro registro foi em 1733. Ela passou por inúmeras transformações nas últimas décadas que alteraram as condições de concorrência e competitividade desse segmento. Desde a consolidação da produção em Morretes o número de alambiques reduziu drasticamente. A produção de cachaça cresceu muito até aproximadamente os anos de 1950, com cerca de 60 engenhos. Entretanto, com dificuldades dos produtores de dar continuidade a atividade, esses engenhos foram saindo do mercado. Nesse início do século XXI ainda predominam as atividades artesanais, embora ainda com muitas dificuldades de equilíbrio entre os produtores.

Este estudo buscou avaliar essa atividade produtiva artesanal e como ela tem se organizado a partir do Modelo de Muchnik (2006). Conclui-se que os elementos que caracterizam SIAL quando analisado à luz da realidade da produção de Morretes são, ainda, frágeis e insuficientes para sua consolidação. A partir da pesquisa e tomando como base as dimensões, histórica, institucionais, técnica e alimentícia propostas por (MUCHNIK, 2006), os aspectos que tem potencial e frágeis de modo a buscar caracterizar a produção de cachaça de Morretes como um SIAL são: 
Quadro 2: Potencialidades e limites da produção de cachaça

\begin{tabular}{|c|c|c|}
\hline DIMENSÕES & POTENCIALIDADES & LIMITES \\
\hline Histórica & $\begin{array}{l}\text { - Preservação das tradições de cultivo e } \\
\text { produção desde o processo de } \\
\text { colonização; } \\
\text { - Herança das propriedades e herança } \\
\text { culural; } \\
\text { - Sentimento de pertenciamento; }\end{array}$ & $\begin{array}{l}\text { - Atração de novos produtores em } \\
\text { função do reconhecimento do } \\
\text { produto local; }\end{array}$ \\
\hline Institucional & $\begin{array}{l}\text { - Existência de instituições de apoio; } \\
\text { - Busca de organização dos produtores } \\
\text { em torno da IG; } \\
\text { - Cooperação entre produtores (troca de } \\
\text { materiais, conhecimento, etc.); } \\
\text { - Cooperação vinculada a proximidade } \\
\text { geográfica; }\end{array}$ & $\begin{array}{l}\text { - Poder público local tem apoiado } \\
\text { pouco os produtores; } \\
\text { - Linhas de crédito adequadas } \\
\text { para esses produtores } \\
\text { inexistentes; } \\
\text { - SEBRAE e ADETUR envolvidos no } \\
\text { processo IG, trabalham com } \\
\text { produtores formais. } \\
\text {-Baixa cooperação entre } \\
\text { produtores formais e informais; }\end{array}$ \\
\hline Técnica & $\begin{array}{l}\text { - Solo e clima favoráveis ao plantio e } \\
\text { produção da cachaça; } \\
\text { - Saberes } \quad \text { compartilhados } \\
\text { intergerecionalmente; }\end{array}$ & $\begin{array}{l}\text { - Poucas condições de melhoria da } \\
\text { infraestrutura técnica dos } \\
\text { produtores informais; } \\
\text { - Os canais de distribuição do } \\
\text { produto são limitados }\end{array}$ \\
\hline Alimentícia & $\begin{array}{l}\text { - Cultura de consumo e produção da } \\
\text { cachaça; } \\
\text { - Região com potencial turístico; } \\
\text { - Potencial de articulação cesta de bens. }\end{array}$ & $\begin{array}{l}\text { - Baixa articulação com o setor } \\
\text { turístico; } \\
\text { - Pouca divulgação do produto } \\
\text { por parte dos produtores } \\
\text { informais; }\end{array}$ \\
\hline Sustentabilidade & $\begin{array}{l}\text { - Uso de fertilizantes e processos } \\
\text { orgânicos de cultivo; } \\
\text { - Uso de recursos renováveis; } \\
\text { - Unidades de conservação; } \\
\text { - Há paisagens favoráveis a integração do } \\
\text { turismo ao processo de comercialização; }\end{array}$ & $\begin{array}{l}\text { - Alguns produtores utilizam } \\
\text { fertilizantes; } \\
\text { - Pouca preocupação com a } \\
\text { preservação das UCs locais. } \\
\text { - Conflitos com os órgãos de } \\
\text { fiscalização ambientais. }\end{array}$ \\
\hline
\end{tabular}

Fonte: Elaborado pelos autores.

Por meio do quadro 2 percebe-se que a produção de cachaça de Morretes é uma atividades que faz parte da história da região. Tem sido mobilizada como herança de seus antepassados e tem servido para promoção de um tipo de economia mais favorável ao um modelo de desenvolvimento alternativo. Os processos produtivos da cachaça de Morretes buscam preservar os recursos naturais, usando-os de forma consciente, reaproveitando o máximo possível desses recursos - água e energia elétrica.

Para promover um modo de organização produtiva mais compatível com o DTS faz-se necessário que os atores locais fortaleçam seus vínculos e trabalhem em busca de uma estratégia coletiva. As relações entre os atores podem ser consideradas como ativos específicos do território. Todavia, tais relações na região pesquisada ainda são embrionárias. Há o compartilhamento das histórias e experiências locais no território pesquisado e tal aspecto é considerado elemento fundamental para o capital social (REQUIER-DESJARDINS et al., 2006).

Há, também, alguns limites institucionais, tanto de articulação entre organizações produtoras da cachaça (engenhos), quanto das instituições de apoio como SEBRAE e ADETUR. Ou seja, há falta de articulação e compartilhamento de 
projetos, o que torna essa atividade pouco organizada e com baixa produtividade. Conclui-se que a atividade de produção da cachaça de Morretes é uma organização produtiva em que os recursos específicos foram parcialmente ativados. A produção de cachaça de Morretes está estagnada ou em declínio.

O processo de IG, aparentemente, não está promovendo o DTS e sim a desigualdade entre os produtores, pois a maioria dos produtores estão fora desse processo. Nesse segmento prevalece a produtividade, caminho inverso do que é proposto pelo SIAL e DTS. A IG poderia ser uma saída para o avanço da produção com uma outra lógica que não a de mercado exclusivamente. Para tanto, faz-se necessário incorporar os estabelecimentos que não estão no processo, os produtores informais, mas para tal necessita da ajuda do poder público e das instituições de fomento. Essas instituições são fundamentais, primeiramente para tornar os empreendimentos ilegais em legais e, em consequência, avançarem para a IG, dando continuidade dessa importante atividade tradicional e cultural da região evitando as extinção dos produtores ileguais. Para futuras pesquisas tem-se o desafio de pensar o DTS como passagem da estratégia de IG para uma cesta de bens. Evitando que a estratégia de IG beneficie poucos produtores, geralmente os mais consolidados, gerando mais crescimento econômico que desenvolvimento (DENARDIN, 2016).

A cesta de bens seria uma alternativa para promoção do DTS (DENARDIN, 2016), buscando engajar outros municípios do litoral do Paraná, ao associar o turismo e outros empreendimentos, com intuito de fortalecer o desenvolvimento integral, promovendo um ganho plural. Há necessidade de um maior engajamento da sociedade civil local, dos empreendedores locais e do poder público. A existência de uma paisagem que promove o turismo, em função das UCs (Área de Especial Interesse Turístico - AIET do Marumbi, Área de Proteção Ambiental - APA Estadual de Guaratuba, Parque Estadual da Graciosa, Parque Estadual do Pau Oco, Parque Estadual Pico do Marumbi e Parque Estadual Roberto Ribas Lange), bem como a preservação da cultura local, por meio do barreado entre outras comidas típicas, podem ser considerados ativos específicos a serem incorporados na cesta de bens do litoral do Paraná.

\section{REFERÊNCIAS}

AGÊNCIA DE DESENVOLVIMENTO DO TURISMO SUSTENTÁVEL DO LITORAL DO PARANÁ (ADETUR). Gestão e Políticas. Disponível em:<

https://adeturlitoral.com.br/gestatildeo-e-politicas.html> Acesso em: 25 mar.2019.

AMBROSINI, L. B.; FILIPPI, E. E.; MIGUEL L. A. SIAL: análise da produção agroalimentar a partir de um aporte territorialista e multidisciplinar. Revista IDeAS, Rio de Janeiro, v. 2, n. 1, p. 6-31, jan.-jun. 2008.

ANACLETO, A.; MACHADO, A.; SILVA, F, J, A. Estratégias de comercialização de aguardente artesanal no litoral paranaense. Revista de Administração da UEG, Aparecida de Goiânia, v.5, n.1, jan./abr. 2014. 
AREND, S. C; DEPONT, C. M; SILVEIRA, R. L. L; SILVEIRA, R. C. E.; BRANDT, G. B.; ZANCHI, V. Observando o desenvolvimento regional do vale do rio pardo: notas sobre as dinâmicas econômicas recentes. Barbarói, Santa Cruz do Sul, n.54, p., jul./dez. 2019.

BARDIN, L. Análise de conteúdo. Lisboa: Edições 70 Ltda, 1977.

BORGES, L. A imigração italiana em Morrretes. Curitiba. Editora o formigueiro, 1990.

CAVAGNOLLI, S. M. Morretes: passado sem ruinas - Morretes: Grafica e editora Stella Maris, 1995.

CAZELLA, Ademir Antonio et al. A construção de um território de desenvolvimento rural: recursos e ativos territoriais específicos. Redes, Santa Cruz do Sul, v. 24, n. 3, p. 49-74, sep. 2019. ISSN 1982-6745. doi: https://doi.org/10.17058/redes.v24i3.14118.

CERVO, A. L.; BERVIAN, P. A.; DA SILVA, R. Metodologia Científica, 6. Ed., São Paulo: Pearson Prentice Hall, 2007.

CIRAD/SAR. Systèmes agroalimentaires localisés (organisations, innovations et développement local). Proposition d'animationscientifiquedulaboratoire STSC, n. 134/96. 1996.

COURLET, C. Os sistemas produtivos localizados : da definicão ao modelo. Eisforia, Florianópolis, v.4, n. especial, p. 1 - 336, dez. 2006.

DENARDIN, V. F.; KOMARCHESKI, R.; SULZBACH, M. T. Farinheiras no Litoral do Paraná: uma análise a partir da noção de sistema agroalimentar localizado: SIAL Farinheiras. IN: DENARDIN, Valdir Frigo; KOMARCHESKI, Rosilene (Orgs.). Farinheiras do Brasil: tradição, cultura e perspectivas da produção familiar de farinha de mandioca. Matinhos: Editora UFPR Litoral, 2015. p. $197-217$.

DENARDIN, V.F. Desenvolvimento Territorial e Estratégias de Valorização da Origem de Bens Alimentares. $O$ sabor da origem: produtos territorialidades na nova dinâmica dos mercados alimentares. Porto Alegre: Escritos do Brasil, 2016.

DENARDIN, V. F. et al. Distribuição de benefícios ecossistêmicos: o caso do ICMS ecológico no litoral paranaense. Redes, Santa Cruz do Sul, v. 13, n. 2, p. 184-198, maio/ago. 2008.

DRUMM, E. C.; SILVEIRA, R. L. L.; BRANDT, G. B. A Reconfiguração do Espaço Urbano e a Apropriação da Cultura Como Meio de Acumulação

Capitalista. Desenvolvimento em Questão, v. 16, n. 43, p. 147-174, 2018.

ESTADES, N. P. O litoral do Paraná: entre a riqueza natural e a pobreza social. Desenvolvimento e Meio Ambiente, Curitiba, n. 8, p. 25-41, jul/dez. 2003. 
FIESC - Federação das Indústrias do Estado de Santa Catarina, 2018. Disponível em: <http://www4.fiescnet.com.br/pt/setores/agroalimentar> Acesso em: 16 set. 2018.

FILHO, A. J. T. Produção de cana-de-açúcar e qualidade da cachaça em Morretes, Pr. Dissertação (Curso de Pós-Graduação em Agronomia) - Universidade Federal do Paraná, Curitiba/PR, 2008.

GUIMARÃES, G, M.; BALEM, T. A.; SILVEIRA, P. R. C.; ZIMMERMANN, S. A.O rural contemporâneo em debate: temas emergentes e novas institucionalidades. ljuí-RS: Unijuí, 2015.

INSTITUTO BRASILEIRO DE GEOGRAFIA E ESTATÍSTICA - IBGE. Censo Demográfico 2010: Resultados gerais da amostra. Disponível em: <

https://cidades.ibge.gov.br/brasil/pr/morretes/panorama>. Acesso em: 14 set. 2018.

INSTITUTO PARANAENSE DE ASSISTÊNCIA TÉCNICA E EXTENSÃO RURAL DO PARANÁ (EMATER - PR). Missão, visão e papéis. Disponível em:< http://www.emater.pr.gov.br/modules/conteudo/conteudo.php?conteudo=45> Acesso em: 18 de maio de 2019.

INSTITUTO PARANAENSE DE DESENVOLVIMENTO ECONÔMICO E SOCIAL IPARDES. Cadernos Municipais, 2018. Disponível em:<http://www.ipardes.gov.br/cadernos/MontaCadPdf1.php?Municipio=83350 $>$. Acesso em: 13 set. 2018.

KNOPIK, M. A.; FLEIG, D. Perspectivas da Cadeia Produtiva da Cana-de-Açucar no Sistema Orgânico. O caso de Morretes, PR. Rev. Bras. De Agroecologia/nov. 2009 Vol. 4 No. 2

LEAL, C. T. Conselho do Litoral: gestão democrática do espaço costeiro. R. paran. Desenv., Curitiba, n. 99, p. 83-95, jul./dez. 2000.

MEIRA, E. D. A cachaça morretiana e seus usos turísticos na contemporaneidade. Cadernos do CEOM - Ano 26, n. 39 - Economia Criativa e Economia da Cultura, dez. 2013.

. História de um patrimônio cultural: a cachaça morretiana. Dissertação (Mestrado) - Universidade da Região de Joinville - Univille - Joinville - SC 2013.

MENEZES, E. C. de O. INDUSTRIALIZAÇÃO E MEIO AMBIENTE NO ESTADO DE SANTA CATARINA. Estudo de caso sobre a evolução e os impactos socioambientais do segmento têxtil-vestuarista na microrregião do Alto Vale do Itajaí. Tese (doutorado)- Universidade Federal de Santa Catarina, Centro de Filosofia e Ciências Humanas, Programa de Pós-Graduação em Sociologia Política, Florianópolis, 2009.

MORRETES. Prefeitura Municipal, 2018. Disponível em: <http://www.morretes.pr.gov.br/index.php/municipio>. Acesso em: 13 set. set. 2018. 
MUCHNIK, J. Sistemas agroalimentarios localizados: evolución del concepto y diversidade de situaciones. In: III Congreso Internacional de lared sial: alimentación y territórios. Baeza, España. p. 18-21, oct. 2006.

MUCHNIK, J. et al. Systèmes Agroalimentaires Localisés. Dossier Systèmes agroalimentaires localisés. Economies et Sociétés., n. 29, p. 1465-1484, sep. 2007.

MUCHNIK, J.; CAÑADA, J. S.; SALCIDO, G. T. Systèmes agroalimentaires localisés: état des recherches et perspectives. CahiersAgricultures v. 17, n. 6, nov-déc. 2008.

MUCHNIK, J. Sistemas agroalimentarios localizados: desarrollo conceptual y diversidad de situaciones. In: SALCIDO, G. T.; TORRES, R. M. L. Los sistemas agroalimentarios localizados: Identidad territorial, construcción de capital social e instituciones. Colección Alternativas. México: Imprensa Juan Pablos, 2012. p. 25-42.

OSTA, B. R. L. Bola de Neve Virtual: O Uso das Redes Sociais Virtuais no Processo de Coleta de Dados de uma Pesquisa Científica. Revista Interdisciplinar de Gestão Social, v. 7, n. 1, p. 15-37, 2018.

PECQUEUR, B. A guinada territorial da economia Global. Eisforia, Florianópolis, v.4, n. especial, p. 1 - 336, dez. 2006.

. Qualidade e desenvolvimento territorial: a hipótese da cesta de bens e de serviços territorializados. Eisforia, Florianópolis, v.4, n. especial, p. 1 - 336, dez. 2006.

. B. O desenvolvimento territorial: uma nova abordagem dos processos de desenvolvimento para as economias do sul. Florianópolis: Raízes, v. 24, n.1-2, p. 1022, jan./dez. 2005.

PORTAL MORRETES. Cachaça: a legitima morretiana. Disponível em:<https://www.morretes.com/cachaca-a-legitima-morretiana/>. Acessoem: 03 ago. 2017.

PORTO MORRETES. Cachaça orgânica. Disponível em: <https://www.portomorretes.com.br/pagina/cachaca-organica.html>. Acesso em: 23 mai. 2019.

REQUIER-DESJARDINS, D; BOUCHER, FRANÇOIS; CERDAN, C. Globalização, vantagens competitivas e sistemas agroindustriais localizados em zonas rurais de países latino-americanos. Eisforia, Florianópolis, v.4, n. especial, p. 1 - 336, dez. 2006.

SACHS, I. Prefácio. In: VEIGA, J.E. Desenvolvimento sustentável: o desafio do século XXI.2 ed. Rio de Janeiro: Garamond, 2006.

. Desenvolvimento includente, sustentável, sustentado. Rio de Janeiro:

Garamond, 2004. 
. Ecodesenvolvimento: Crescer sem Destruir. São Paulo: Vértice, 1986.

. Rumo a ecossocioeconomia: Rumo à ecossocioeconomia: teoria e prática do desenvolvimento. Paulo Freire Vieira (org.). São Paulo: Cortez, 2007.

SANTOS, I. A. F.; DIESEL, V. Agência dos agricultores na interface dos sistemas formal e informal de conhecimento e inovação. Redes, v.25, n.1, p. 32-58, janeiroabril, 2020.

SCHUMPETER, J. A. Teoria do desenvolvimento econômico: uma investigação sobre lucros, capital, crédito, juro e o ciclo econômico. Tradução: Maria Sílvia Possas. São Paulo: Abril Cultural, 1982.

SERVIÇO BRASILEIRO DE APOIO ÀS MICRO E PEQUENAS EMPRESAS (SEBRAE). Indicações Geográficas do Litoral do Paraná. Disponível em:<http://www.sebraepr.com.br/PortalSebrae/sebraeaz/Indica\%C3\%A7\%C3\%A30Geogr\%C3\%A1fica> Acesso em: 03 ago. 2017.

SIQUEIRA, C. M. Sistema agroalimentar localizado (sial) e as atividades de comunidades do entorno da pr - 508 (rodovia alexandra-matinhos). Dissertação (Mestrado) - Universidade Federal do Paraná - Setor Litoral, Matinhos/PR, 2016.

SPECHT, S. O território do morango no Vale do Caí/RS: análise pela perspectiva dos sistemas agroalimentares localizados. Tese (Doutorado) - Universidade Federal do Rio Grande do Sul - Porto Alegre, 2009.

VEIGA, J. E. Desenvolvimento sustentável: o desafio do século XXI. 3 ed. Rio de Janeiro: Garamond, 2006.

. Desenvolvimento sustentável, que bicho é esse? / José Eli da Veiga \& Lia Zatz. - Campinas, SP: Autores Associados, 2008.

VIEIRA, P. F. Rumo ao desenvolvimento territorial sustentável: esboço de roteiro metodológico participativo. Eisforia: desenvolvimento territorial sustentável: conceitos, experiências e desafios teórico-metodológicos. Florianópolis, v. 4, n. especial, dez. 2006.

. Políticas ambientais no Brasil: Do preservacionismo ao desenvolvimento territorial sustentável. Política \& Sociedade. n. 14, abril. 2009.

Elaine Cristina de Oliveira Menezes. Doutora em Sociologia Política Universidade Federal de Santa Catarina. Professora Adjunta do Curso de Administração Pública e do Programa de Pós-Graduação em Desenvolvimento Territorial Sustentável da Universidade Federal do Paraná. Rua Jaguariaíva, 512, Caiobá, Matinhos, Paraná, CEP: 83260-000. E-mail: eoliveira.menezes@gmail.com. 
Eder Bruno Couto Curvelo. Mestre em Desenvolvimento Territorial Sustentável pela Universidade Federal do Paraná - Setor Litoral. Especialista em Administração de Empresas e Sustentabilidade pela Universidade Estadual do Paraná - Campus Paranaguá. Rua Julio Groth Elias, 999, Jardim Samambaia, CEP 83.212-415, Paranaguá-PR. E-mail: ebc.carangola@hotmail.com.

Sandro Deretti. Doutor em Administração pela PUCPR. Professor Adjunto do Curso de Graduação em Administração e do Programa de Pós Graduação em Ambientes Litorâneos e Insulares - PALI. Rua Comendador Correa Jr., 117 Centro. CEP 83.203-560 Paranaguá, PR. E-mail sandro.deretti@unespar.edu.br

Como citar: MENEZES, Elaine Cristina de Oliveira; CURVELO, Eder Bruno Couto; DERETTI, Sandro. Sistema Agroalimentar Localizado e Desenvolvimento Territorial Sustentável: um estudo da experiência dos produtores de cachaça do município de Morretes - PR. Redes (St. Cruz Sul, Online), Santa Cruz do Sul, v. 25, p. 2524-2548, 2020. ISSN 1982-6745. doi:https://doi.org/10.17058/redes.v25i0.15071.

\section{CONTRIBUIÇÃO DE CADA AUTOR}

a. Fundamentação teórico-conceitual e problematização: Eder Bruno Couto Curvelo, Elaine Cristina de Oliveira Menezes e Sandro Deretti.

b. Pesquisa de dados e análise estatística: Éder Bruno Couto.

c. Elaboração de figuras e tabelas: Eder Bruno Couto Curvelo e Elaine Cristina de Oliveira Menezes.

d. Fotos: : não há fotos.

e. Elaboração e redação do texto:, Elaine Cristina de Oliveira Menezes, Eder Bruno Couto Curvelo e Sandro Deretti.

f. Seleção das referências bibliográficas: Elaine Cristina de Oliveira Menezes, Sandro Deretti e Eder Bruno Couto Curvelo.

Fontes de financiamento: Não houve. 